\title{
CARACTERIZAÇÃO MORFOMÉTRICA DA BACIA HIDROGRÁFICA DO CÓRREGO IMBIRUSSU - CAMPO GRANDE, MS.
}

\author{
Rennan Vilhena Pirajá ${ }^{1}$
}

\author{
Mauro Henrique Soares da Silva ${ }^{2}$
}

\begin{abstract}
RESUMO
O trabalho tem como objetivo apresentar a caracterização morfométrica da Bacia hidrográfica do Córrego Imbirussu obtida através de Sensoriamento Remoto e Sistema de Informações Geográficas, no qual foi utilizada imagem SRTM (Shuttler radar topography mission). A bacia do Imbirussu possui uma área de $119,2 \mathrm{~km}^{2}$ e um perímetro de $67 \mathrm{~km}$. A densidade de drenagem obtida foi de $0.3 \mathrm{~km} / \mathrm{km}^{2}$, assim como, o coeficiente de compacidade foi de 1,71 e o fator de forma de 0,29. A amplitude topográfica da bacia é de $165 \mathrm{~m}$ e sua declividade foi classificada como plano/praticamente plano e suave ondulado. $O$ córrego Imbirussu percorre um trecho de $24,7 \mathrm{~km}$ até atingir seu exutório, no Rio Anhandui, tendo uma porção à montante, onde foi registrada a maior quantidade de episódios de enchentes e inundações, ocupada pela área urbana da cidade de Campo Grande - MS. A análise dos dados morfométricos demonstrou que a bacia do Córrego Imbirussu apresenta, em seu estado natural, baixa probabilidade de enchentes, é de fácil à média permeabilidade e, por possuir um relevo plano/praticamente plano na maior porção de sua área deduz-se que o seu escoamento superficial é lento e que em condições naturais há boa capacidade de absorção. Assim, os impactos ambientais ocasionados por enchentes na região urbana do Imbirussu estão associados à impermeabilização do solo e a ocupação nas proximidades de fundo de vale, principalmente na área de confluência do córrego Imbirussu com o córrego Serradinho onde se concentra o maior fluxo de água acumulado dentro da área urbana.
\end{abstract}

PALAVRAS - CHAVE: Estudos morfométricos; Uso e Ocupação do solo; Impactos ambientais.

\section{MORPHOMETRIC CHARACTERIZATION OF RIVER WATERSHED STREAM IMBIRUSSU - CAMPO GRANDE, MS.}

\section{ABSTRACT}

The work aims to present a morphometric characterization of the Watershed Stream Imbirussu obtained through Remote Sensing and Geographic Information System, where SRTM image was used (Shuttler

\footnotetext{
${ }^{1}$ Geógrafo, doutorando em Meio Ambiente e Desenvolvimento Regional - Anhanguera/UNIDERP. rennanvp@hotmail.com

2 Geógrafo, Doutor em geografia pela UNESP Professor do Programa de Mestrado e Doutorado em Meio Ambiente e Desenvolvimento Regional - Univ. ANHANGUERA UNIDERP.mauro.soares@uniderp.edu.br
} 
radar topography mission). The Watershed of Imbirussu has an area of $119.2 \mathrm{~km}^{2}$ and a circumference of $67 \mathrm{~km}$. Drainage density obtained was $0.3 \mathrm{~km} / \mathrm{km}^{2}$, as well as the compactness coefficient was 1.71 and the form factor of 0.29. The topographic amplitude of the watershed is 165 me its slope was classified as flat / nearly flat and gently undulating. The Imbirussu stream traverses a stretch of $24.7 \mathrm{~km}$ to reach its discharge in Rio Anhanduí, having an upstream portion, where there was a greater number of episodes of floods and inundations, occupied by the urban area of Campo Grande - MS. The analysis of morphometric data showed that the Watershed Stream Imbirussu has a low probability of flooding, the area is easy to average permeability and that by owning a flat relief / almost flat throughout most of its area is deduced that the runoff and that surface is slow under natural conditions there is good absorption capacity. It was also found that the environmental impacts caused by floods in the urban region of Imbirussu are associated with soil sealing and occupation near the valley bottom, mainly in the area of confluence of the stream with Imbirussu Serradinho stream which concentrates the largest flow water accumulated within the urban area.

KEY - WORDS: morphometric studies; Use and Occupancy soil; environmental impacts.

\title{
MORFOMÉTRICO CARACTERIZACIÓN DE CUENCA DEL RÍO CORRIENTE IMBIRUSSU - CAMPO GRANDE, MS.
}

\begin{abstract}
RESUMEN
El trabajo tiene como objetivo presentar una caracterización morfométrica de la Cuenca del Arroyo Imbirussu obtenida a través del Sistema de Información Geográfica y Teledetección, donde se utilizó la imagen SRTM (Shuttler radar misión topografía). La Cuenca del Imbirussu tiene una superficie de 119,2 kilometros ${ }^{2}$ y una circunferencia de 67 kilómetros. Densidad de drenaje obtenido fue de $0,3 \mathrm{~km} / \mathrm{km}^{2}$, así como el coeficiente de compacidad era 1,71 y el factor de forma de 0,29. La amplitud topográfico de la cuenca es de 165 me su pendiente se clasificó como plana / casi plana y suavemente ondulado. La corriente Imbirussu atraviesa un tramo de $24,7 \mathrm{~km}$ para llegar a su descarga en Río Anhanduí, que tiene una parte de aguas arriba, donde había un mayor número de episodios de inundaciones y las inundaciones, que ocupa la zona urbana de Campo Grande - MS. El análisis de los datos morfométricos mostraron que la Cuenca del Arroyo Imbirussu tiene una baja probabilidad de inundación, la zona es fácil de permeabilidad media y que por poseer un relieve plano / casi plana a lo largo de la mayor parte de su área se deduce que la segunda vuelta y que la superficie es lento en condiciones naturales existe una buena capacidad de absorción. También se encontró que los impactos ambientales causados por las inundaciones en la región urbana de Imbirussu están asociados con el sellado del suelo y la ocupación cerca del fondo del valle, principalmente en la zona de confluencia del arroyo con corriente Imbirussu Serradinho que concentra el flujo más grande agua acumulada dentro del área urbana.
\end{abstract}

PLABRAS-CLAVE: Estudios morfométricos; Uso y ocupación del suelo; Impactos ambientales.

\section{INTRODUÇÃO}

Uma bacia hidrográfica pode ser considerada como um espaço drenado por um rio principal, seus afluentes e subafluentes permanentes ou intermitentes. Segundo Santos (2004) seu conceito está associado à noção de sistema, nascentes, divisores de águas, cursos d'água hierarquizados e foz. Os eventos que acontecem em uma 
bacia hidrográfica sejam eles de origem antrópica ou natural refletem na dinâmica desse sistema, assim como na quantidade de água dos cursos e na sua qualidade.

Conforme Guerra (2010) o comportamento das condições naturais e das atividades humanas desenvolvidas nas bacias hidrográficas traduzem-se em mudanças significativas em qualquer dessas unidades e podem gerar alterações, efeitos e/ou impactos a jusante e nos fluxos energéticos de saída (descarga, cargas sólidas e dissolvida).

Conforme Tundsi (2011) a bacia hidrográfica tem certas características essenciais que a torna uma unidade muito bem caracterizada e permitem a integração multidisciplinar entre diferentes sistemas de gerenciamento, estudo e atividade ambiental. Tendo como uma de suas principais vantagens a sua unidade física com fronteiras delimitadas que podem estender-se por várias escalas espaciais desde as grandes bacias hidrográficas até as microbacias.

Para Anastácio (2004) a bacia hidrográfica é a unidade básica de planejamento para a compatibilização da preservação dos recursos naturais e da produção agropecuária. As bacias hidrográficas possuem características ecológicas, geomorfológicas e sociais integradoras, o que possibilita a abordagem holística e participativa, envolvendo estudos interdisciplinares para o estabelecimento de formas de desenvolvimento sustentável inerentes ao local e região onde forem implementados.

Diante deste contexto, para Teodoro et. al. (2007) a caracterização morfométrica torna-se um dos mais importantes levantamentos realizados em análises hidrológicas ou ambientais devido ao fato de apresentar dados importantes para o melhor entendimento da dinâmica ambiental local e/ou regional.

Segundo IBGE (2009) o conjunto das análises morfométricas é de fundamental importância para o reconhecimento da espacialidade do sistema, entre outros, quanto às características de área e da rede de drenagem, pois possibilitam gerar informações passiveis de utilização em generalizações em bacias hidrográficas.

A área de estudo deste trabalho corresponde á bacia hidrográfica do Córrego Imbirussu e está localizada no município de Campo Grande, Mato Grosso do Sul, sendo o córrego Imbirussu o seu curso principal e tributário do Rio Anhandui. 
É caracterizada por ser uma bacia bastante impactada, com problemas de poluição hídrica, devido às atividades de origem antrópica e os processos de uso e ocupação do solo, no qual sua porção à montante é ocupada pela área urbana, por um polo empresarial e um distrito industrial. Segundo a PLANURB (1991) a forma de ocupação relacionada com suas características físicas de relevo e solo apresentam problemas como alagamentos localizados em função das dificuldades de escoamento das águas pluviais e servidas nas áreas urbanizadas de baixa declividade (menor que $3 \%)$.

Conforme Antônio (2012) 45\% dos episódios de enchentes e inundações registrados na área urbana da cidade de Campo Grande ocorreram na região do Imbirussu.

Estando a cidade de Campo Grande praticamente toda assentada sobre as sub-bacias contribuintes do Rio Anhanduí, este trabalho justifica-se por colaborar para um melhor entendimento da dinâmica dos processos físicos e antrópicos em bacias hidrográficas.

O objetivo deste trabalho foi realizar a caracterização dos aspectos morfométricos da bacia hidrográfica do Córrego Imbirussu, no qual foram levantados alguns parâmetros físicos, tais como: área da bacia, perímetro, densidade de drenagem, coeficiente de compacidade, fator de forma, perfil longitudinal do córrego Imbirussu, hierarquia fluvial, amplitude topográfica, curva hipsométrica e declividade da bacia. Através da análise destes dados pretende-se contribuir para fins de planejamento e para o melhor conhecimento da dinâmica de bacias hidrográficas.

\section{MATERIAIS E MÉTODOS}

\section{1 ÁREA DE ESTUDO}

A área de estudo refere-se à bacia do Córrego Imbirussu localizada na porção oeste da cidade de Campo Grande - MS, a qual está inserida na sub-bacia do Rio Anhanduí, que por sua vez faz parte da Bacia Hidrográfica do Rio Paraná.

A área da bacia é composta por alguns canais de drenagem, que abrangem dentro do perímetro urbano cinco bairros (José Abrão, Panamá, Popular, Nova Campo Grande e Núcleo Industrial) e parte de sete outros bairros (Nasser, Santo Amaro, 
Santo Antônio, Sobrinho, Taveirópolis, São Conrado e Caiobá) além da área rural fora do perímetro urbano.

Esta bacia hidrográfica tem como canal principal o córrego imbirussu, que tem como nascentes, uma lagoa localizada dentro de um condomínio residencial e a segunda um afloramento de água que, segundo órgãos governamentais, já é prejudicada pelo desmatamento por implantação de lavouras e pastagens no local, além de, ao longo de seu curso receber efluentes domésticos e industriais (PMCG, 2010).

A área possui solo predominantemente Latossólico, seu relevo é composto por platôs e colinas, com áreas praticamente planas e suave onduladas com embaciamentos localizados, sua base litológica é formada por basaltos e arenitos intertrapianos da formação Serra Geral com níveis d'água variando de 4 a $7 \mathrm{~m}$ de profundidade na margem esquerda e em grande parte da margem direita muito próximo a superfície com até 3 metros de profundidade (PLANURB, 1991).

\subsection{LEVANTAMENTO FISIOGRÁFICO DA BACIA DO IMBIRUSSU}

As características físicas dimensionais da bacia hidrográfica do Imbirussu, tais como: área e perímetro, assim como, comprimento do canal principal, comprimento total dos rios e os mapas de declividade, hipsométrico e de fluxo de acumulação de água foram determinados a partir de uma base cartográfica SRTM (Shuttler Radar Topography Mission), que são imagens captadas por sensores de visada vertical e lateral capazes de produzir três dimensões espaciais do relevo: latitude, longitude e altitude $(x, y, z)$ e que são importantes instrumentos para estudos quali/quantitativos (CARVALHO e BAYER, 2008).

Para o presente estudo utilizou-se da carta sf-21-x-b fornecida pelo banco de dados geomorfométricos do projeto TOPODATA (EMBRAPA, 2011), a partir da qual foram extraídas as características físicas de área, perímetro e comprimento dos canais fluviais da bacia em um Sistema de Informações Geográficas utilizando-se o software Arcgis 10 fornecido pelo laboratório de geoprocessamento da UniderpAnhanguera. 
Para a obtenção dos dados morfométricos apresentados neste trabalho utilizou-se a metodologia citada por Villela e Mattos (1975) para o cálculo do coeficiente de compacidade, fator de forma, densidade de drenagem e sinuosidade do curso d'água; a metodologia citada por Christofoletti (1980) para a análise hipsométrica; a classificação citada pela EMBRAPA (2011) para a obtenção do mapa de declividade e a classificação de Strahller (1952 apud VILLELA e MATTOS, 1975) para hierarquia fluvial.

A seguir são apresentadas as características morfométricas utilizadas neste trabalho, organizadas segundo Tonello (2005):

Características geométricas:

- Área da BH (A) - segundo Villela e Mattos (1975) a área de drenagem de uma bacia é a área plana inclusa entre seus divisores topográficos, sendo o elemento básico para o cálculo das outras características físicas, foi expressa em $\mathrm{km}^{2}$.

- Perímetro da $\mathrm{BH}(\mathrm{P})$ - comprimento ao longo dos divisores de água.

- Fator de Forma (Kf) - É a relação entre a largura média e o comprimento axial (La) $(19,9$ km) da bacia. A largura média da bacia é obitida pela área da bacia dividida pelo comprimento da bacia. Este fator constitui um índice indicativo de tendências a enchentes correlacionando a bacia a uma forma retangular e foi obitido pela equação: $K f=A / L^{2}$

- Coeficiente de Compacidade $(\mathrm{Kc})$ - é a relação entre o perímetro da bacia e a circunferência de um círculo de área igual a da bacia. Quanto mais distante da unidade menor a possibilidade de enchentes. $\mathrm{O}$ índice do $\mathrm{Kc}$ foi obitido utilizando-se a equação: $\mathrm{Kc}=0,28 \times \mathrm{P} / \sqrt{ } \mathrm{A}$

\section{Características da rede de drenagem:}

- Comprimento do canal Principal $(L)$ - é o comprimento do rio principal que se estende desde a sua nascente até a sua foz, expressa em km.

- Comprimento total dos rios ( $L t)$ - determinado pela soma do comprimento de todos os canais da bacia, expressa em km.

- Densidade de Drenagem (Dd) - a densidade de drenagem correlaciona o comprimento total dos canais ou rios com a área da bacia hidrográfica. Quanto maior sua densidade de drenagem, mais rapidamente o volume d'água 
originada pelas chuvas chegará ao final da bacia. A densidade de drenagem foi obtida pela equação: $\mathrm{Dd}=\mathrm{Lt} / \mathrm{A}$

- Sinuosidade do curso d'água (Sin) - é a relação entre o comprimento do rio principal (L) e o comprimento do talvegue (Lt) (19,9 km) (o comprimento do talvegue é a medida em linha reta do ponto inicial ao ponto final do curso d'água principal), obtido pela equação: $\operatorname{Sin}=\mathrm{L} / \mathrm{Lt}$

- Número total de segmentos (Nr) - é a quantidade total de canais de acordo com a classificação Strahler (1952).

- Ordem da bacia - Reflete o grau de ramificação ou bifurcação dentro de uma bacia.

\section{Características de relevo:}

- Mapa hipsométrico - Segundo Christofoletti (1980) a hipsometria preocupa-se em estudar as inter-relações existentes em determinada unidade horizontal de espaço no tocante a sua distribuição em relação as faixas altitudinais, indicando a proporção ocupada por determinada área da superfície terrestre em relação às variáveis altimétricas a partir de determinada isoípsa base.

- Curva hipsométrica - É a curva construída pela relação entre o percentual de áreas existentes entre cada faixa altimétrica, representadas em um gráfico e tem a finalidade de exprimir a maneira pela qual o volume rochoso situado abaixo da superfície topográfica está distribuído desde a base até o topo (CHRISTOFOLETTI, 1980)

- Amplitude altimétrica $(\mathrm{Hm})$ - Diferença entre a altitude da desembocadura e a altitude do ponto mais elevado situado em qualquer lugar da divisória topográfica.

- Declividade da bacia - a declividade dos terrenos de uma bacia controla em boa parte a velocidade com que se dá o escoamento superficial, afetando, portanto, o tempo que leva a água da chuva para concentrar-se nos leitos fluviais que constituem a rede de drenagem das bacias (VILELLA e MATTOS, 1975).

\section{RESULTADOS}


Volume 10, Número 2, 2014

Bacias Hidrográficas, Planejamento e Gestão dos Recursos Hídricos

De acordo com a metodologia utilizada foi possível realizar o levantamento das características físicas da bacia do Córrego Imbirussu que são apresentadas na Tabela 1.

Tabela 1: Características físicas da Microbacia do Córrego Imbirussu.

\begin{tabular}{|c|c|c|}
\hline Características Físicas & Resultados & Unidade \\
\hline Área $(\mathrm{A})$ & $\begin{array}{l}119,24163 \\
7\end{array}$ & $\mathrm{~km}^{2}$ \\
\hline Perímetro $(\mathrm{P})$ & 67 & $\mathrm{Km}$ \\
\hline Comprimento total dos cursos fluviais (Lt) & 36,46 & $\mathrm{Km}$ \\
\hline Comprimento do Córrego Imbirussu (L) & 24,74 & $\mathrm{Km}$ \\
\hline Sinuosidade do Córrego Imbirussu (Sin) & 1,23 & - \\
\hline Densidade de drenagem (Dd) & 0,30 & $\mathrm{Km} / \mathrm{km}^{2}$ \\
\hline Coeficiente de compacidade (Kc) & 1,71 & - \\
\hline Fator de forma (Kf) & 0,29 & - \\
\hline Ordem da microbacia & $3^{\circ}$ & - \\
\hline Amplitude altimétrica( $(\mathrm{Hm})$ & 165 & $\mathrm{M}$ \\
\hline Declividade da bacia & $3 \%$ & - \\
\hline
\end{tabular}

A bacia hidrográfica do Imbirussu possui formato alongado, o qual influencia no tempo de escoamento superficial de forma que o fluxo de água tende a se concentrar lentamente no exutório principal, tal característica geométrica da pôde ser inferida através do coeficiente de compacidade de 1,71 e do fator de forma de 0,29.

Para Vilella e Mattos (1975) o coeficiente de compacidade relaciona a proximidade da bacia com um círculo que possui um coeficiente igual a 1 e que quanto maior o Kc haverá menor probabilidade de enchentes na bacia. Nesse mesmo sentido, o fator de forma relaciona-se com um retângulo, ou seja, a área da bacia com o comprimento axial do curso d'água principal, pois, quanto mais distante da unidade $(\mathrm{Kf}=1)$, ou seja, estreita e longa for à bacia, haverá menor probabilidade de enchentes.

Portanto, levando-se em conta apenas essas informações e os dados apresentados pelo coeficiente de compacidade e fator de forma da bacia do Imbirussu, é possível afirmar que, de acordo com suas características geométricas, há menor probabilidade de enchentes. 
Contudo o coeficiente de compacidade e o fator de forma da bacia, apesar deimportantes indicativos do comportamento do sistema hidrológico de uma bacia hidrográfica, o que indica se a bacia é muita ou pouco propensa a picos de enchentes é a análise sistêmica dos dados morfométricos que estão associados às características do relevo e ao sistema de drenagem.

Assim, as características de drenagem estão intimamente ligadas aos parâmetros geométricos da bacia estudada, pois, após a definição do seu contorno observou-se que o canal principal do córrego Imbirussu percorre total de 24,74 km e possui uma elevação média de $530 \mathrm{~m}$. conforme o perfil longitudinal apresentado na figura 1. Verifica-se ainda, que o trecho do córrego Imbirussu que possui maior declividade encontra-se na porção compreendida pelos $5,5 \mathrm{~km}$ iniciais, com topografias entre 530 e $605 \mathrm{~m}$.

Elesbon et al. (2011) ressaltam que a velocidade do fluxo de água de um rio está diretamente ligada a sua declividade. Portanto, a baixa declividade apresentada entre as cotas de 455 e $530 \mathrm{~km}$ com seus 19,24 km restantes indicam que a água escoa em baixa velocidade.

Figura 1 - Perfil longitudinal do Córrego Imbirussu, Campo Grande - MS.

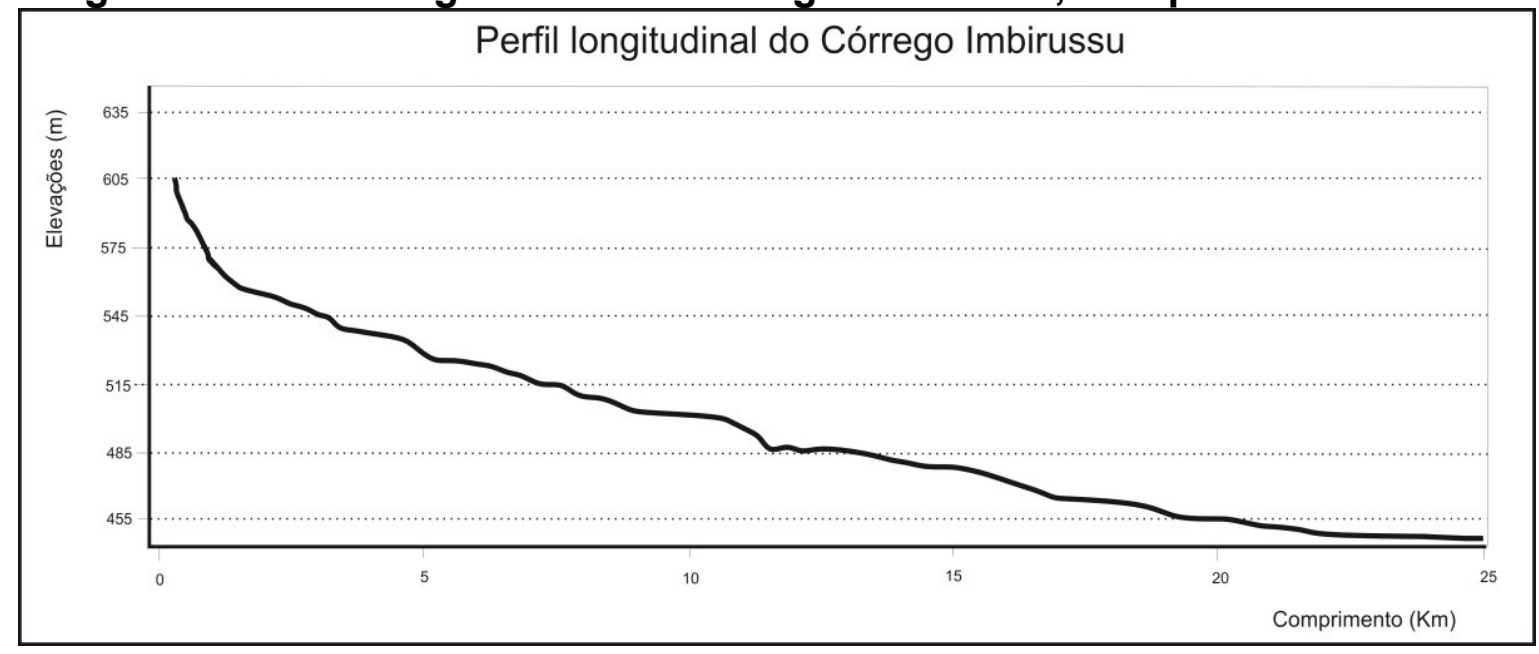

O Comprimento total dos cursos fluviais da bacia do Imbirussu possui 36,46 $\mathrm{km}$, e foi classificada segundo a hierarquia fluvial de Strahler (1957) como de $3^{\circ}$ ordem, área de fácil permeabilidade. Segundo Santos (2004) o grau de ramificação permite ao planejador entender a complexidade do sistema hidrográfico. 
Para Calijuri e Bubel (2006) as microbacias são áreas formadas por canais de $1^{\circ}$ e $2^{\circ}$ ordem e, em alguns casos, de $3^{\circ}$ ordem, devendo ser definida como base na dinâmica dos processos hidrológicos, geomorfológicos e biológicos. As microbacias são áreas frágeis e frequentemente ameaçadas por perturbações, nas quais as escalas espacial, temporal e são fundamentais.

A densidade de drenagem da bacia do Imbirussu é de $0,3 \mathrm{~km} / \mathrm{km}^{2}$. Segundo Vilella e Mattos (1975), este índice infere uma bacia com drenagem pobre, tendo em vista sua classificação que estabelece como parâmetros a variação de pobre $(0,5$ $\mathrm{km} / \mathrm{km}^{2}$ ), ou seja, bacias mal drenadas devida a elevada permeabilidade ou precipitação escassa, à bem drenada $\left(>3,5 \mathrm{~km} / \mathrm{km}^{2}\right)$, bacias excepcionalmente bem drenadas ocorrendo em áreas com elevada precipitação ou muito impermeável.

Segundo Castro (2009) quanto maior o índice menor é a capacidade de infiltrar água, valores baixos indicam que a região é mais favorável à infiltração contribuindo com o lençol freático. Essa variável também se relaciona com os processos climáticos atuantes na área estudada, os quais influenciam o fornecimento e o transporte de material detrítico, pois, a densidade de drenagem está diretamente relacionada à capacidade de erosão fluvial, portanto, quanto maior for a densidade de drenagem, maior será o grau de dissecação do relevo, ou seja, haverá melhor eficiência em transportar sedimentos e maiores vazões em seu curso de água principal. As rochas mais impermeáveis possuem melhores condições para o escoamento superficial, possibilitando a formação de canais e, conseqüentemente, aumentando a densidade de drenagem.

Apresentando um índice de sinuosidade de 1,23, o córrego Imbirussu pode ser classificado como um tipo de canal sinuoso. Conforme Christofoletti (1981) os índices de sinuosidade situados entre 1,1 e 1,5 podem ser considerados como sinuosos, sendo esta categoria transicional entre a dos canais retos e meandrantes, ou seja, à medida que as curvas vão se tornando regulares, frequentes e de amplitude similar o padrão distancia-se do retilíneo e aproxima-se do meândrico. Os fluxos de água que alcançam índices de sinuosidade maior ou igual a 1,5 são considerados meândricos.

A figura 2 ilustra a curva hipsométrica no qual se observa a distribuição da área da microbacia com relação à altitude referente ao nível do mar. 
Figura 2 - Curva hipsométrica do Córrego Imbirussu, Campo Grande - MS.

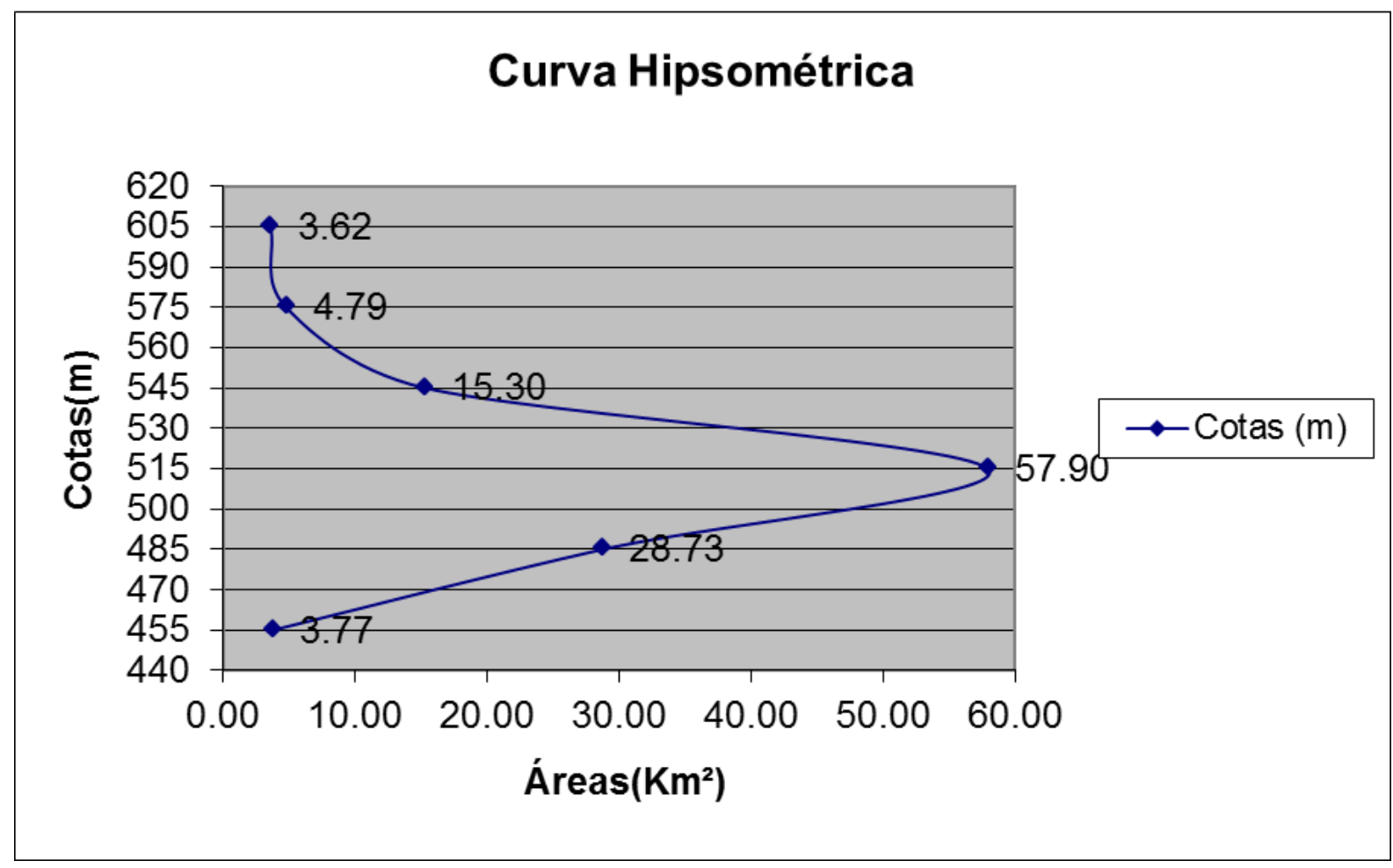

Pode-se verificar que a maior área da bacia com $57,9 \%$ da área total ocorre entre as altitudes de 515 a 545 , onde a declividade da bacia foi classificada como praticamente plana, ocasionando o aumento do tempo para o escoamento superficial pluviométrico e do tempo de concentração das águas no córrego Imbirussu, no entanto proporcionando uma maior capacidade de infiltração.

A declividade da bacia do Imbirussu foi classificada segundo EMBRAPA (2006) de 0 a 3\%, como um relevo plano/praticamente plano, em quase toda sua área de drenagem e de 3 a $8 \%$ como um relevo suave ondulado para as áreas de fundo de vale e áreas mais elevadas, entre as cotas de 560 a $635 \mathrm{~m}$.

$\mathrm{Na}$ figura 3 pode-se inferir que a amplitude topográfica é de $165 \mathrm{~m}$ e que a baixa variação de elevação na bacia do córrego Imbirussu não a torna susceptível a grandes interferências na temperatura e precipitação. 
Figura 3 - Mapa hipsométrico da microbacia do Córrego Imbirussu, Campo Grande - MS.

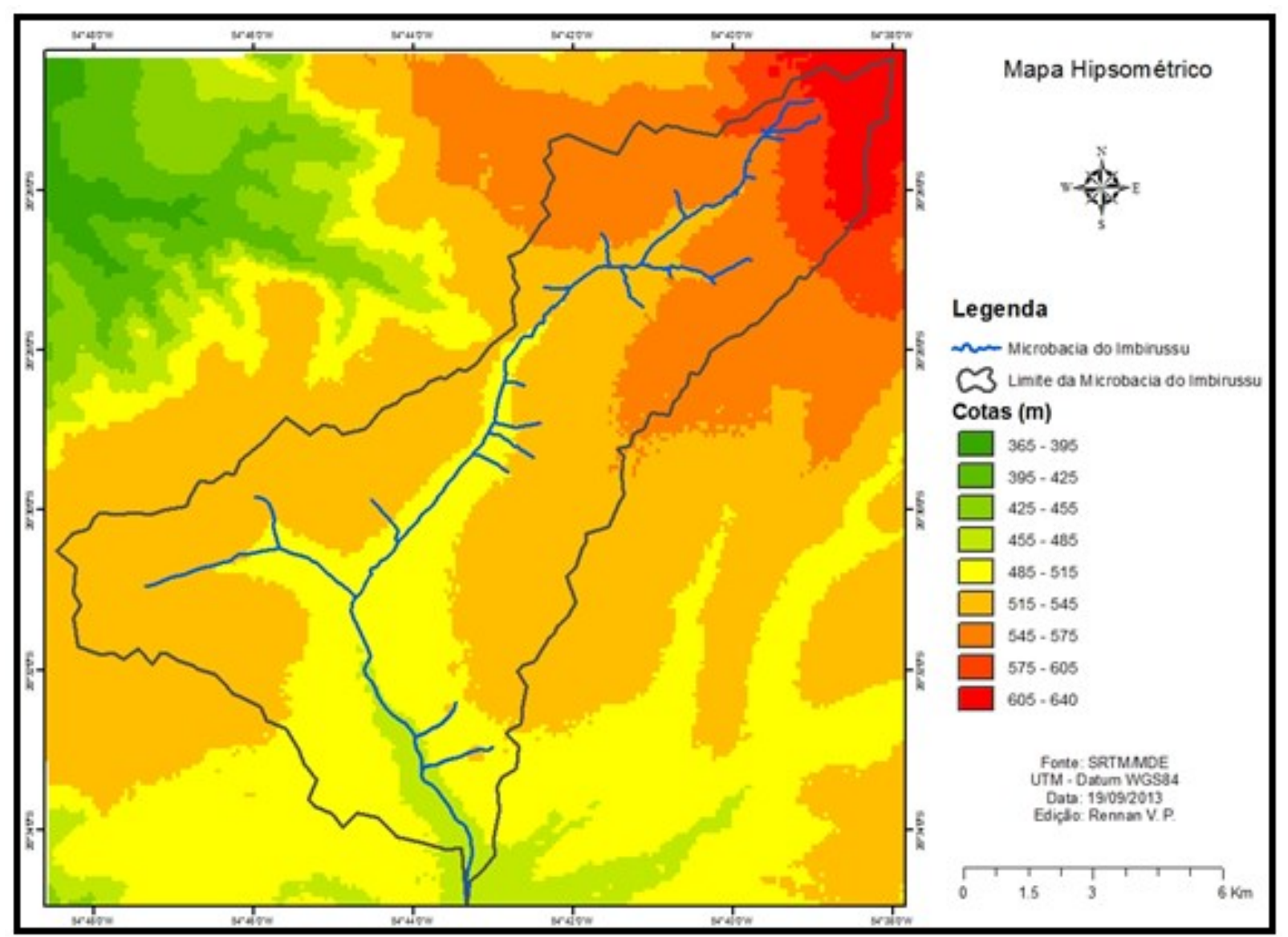

Conforme Vilella e Mattos (1975) a amplitude do relevo influencia não só na perda do material erodido pelo entalhamento do canal, mas também na temperatura e precipitação, pois, a variação da precipitação pela amplitude topográfica, influencia em toda a dinâmica hidrológica da bacia e consequentemente no microclima. Além disso, Villela e Mattos (1975) concordam que a magnitude dos picos de enchente e a maior ou a menor oportunidade de infiltração e susceptibilidade para a erosão dos solos depende da rapidez com que ocorre o escoamento sobre os terrenos da bacia a qual está intimamente ligada à declividade e amplitude topográfica, dentre outras características físicas da área.

Conforme Antônio (2012) um dos principais pontos de enchentes e inundações registrados na região urbana do Imbirussu ocorreram nos bairros Popular e Jardim 
Volume 10, Número 2, 2014

Bacias Hidrográficas, Planejamento e Gestão dos Recursos Hídricos

Aeroporto, situados próximo a confluência dos córregos Imbirussu e Serradinho - P1 (FIGURA 4).

Figura 4 - Mapa de fluxo de acumulação de água e imagem Landsat 5 (TM) da microbacia do Córrego Imbirussu, Campo Grande - MS.

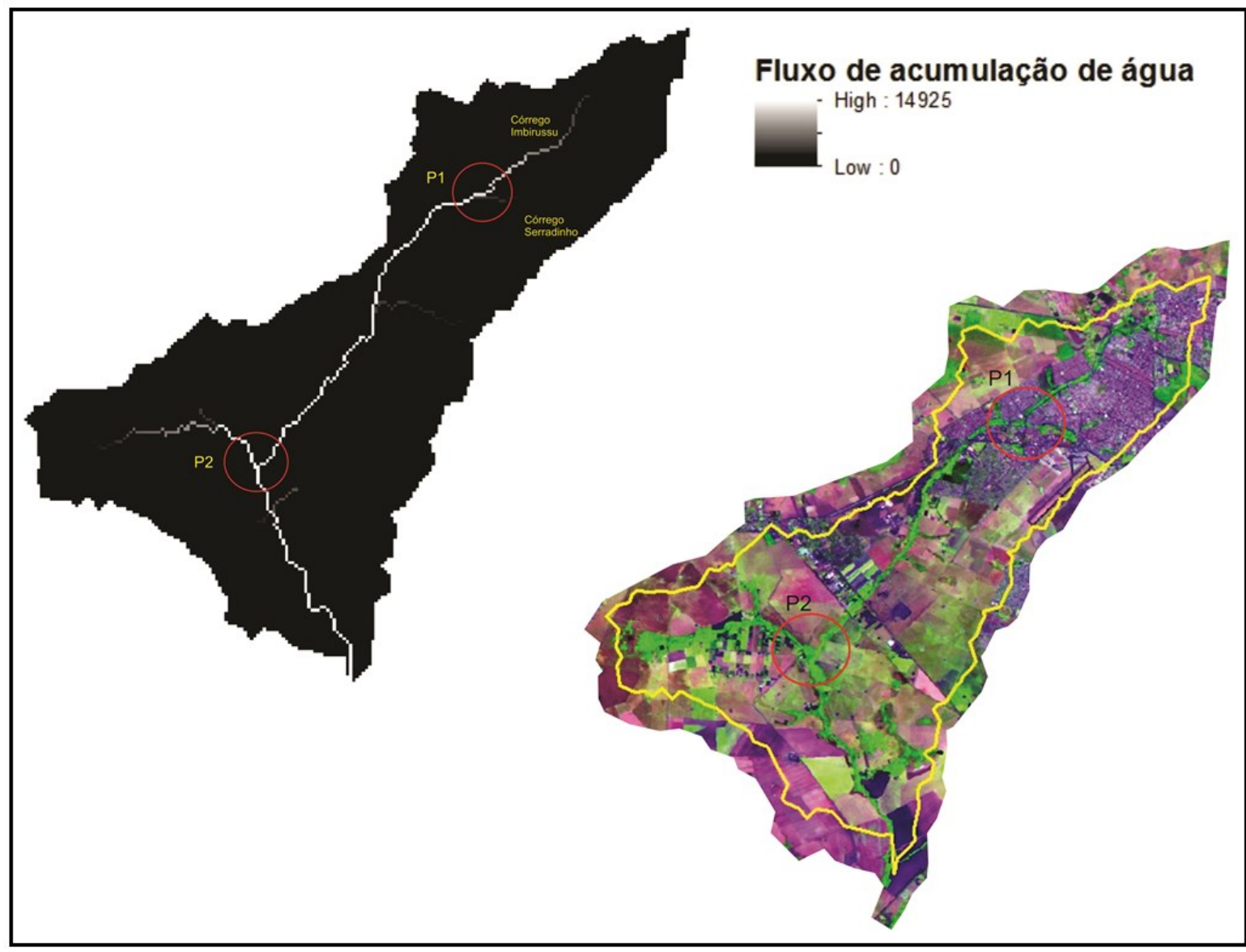

Este tipo de impacto ambiental pode ser interpretado pela forma de ocupação urbana sem planejamento, principalmente nas proximidades do fundo de vale, onde a declividade foi classificada como suave ondulada de 3 a $8 \%$, propiciando alto índice de permeabilização do solo, que impedem a infiltração e aceleram o escoamento superficial diminuindo o tempo de concentração das águas e fazendo a convergência do fluxo de água para a confluência dos córregos Serradinho e Imbirussu, o qual não consegue dar vazão a grande quantidade de água recebida.

No ponto de confluência ( $\mathrm{P} 1)$ também se observa o principal ponto de ruptura de declive, no qual, a partir daí, o canal principal adquire menor amplitude topográfica e a velocidade do fluxo de água passa a perder velocidade.

No entanto, no ponto 2 (P2), o córrego Imbirussu ganha volume de água, conforme indica o mapa de fluxo de acumulação de água, e há um aumento na área 
de capitação da microbacia, além da sua declividade ser classificada como plano/praticamente plano, de 0 a $3 \%$, portanto, a sua futura ocupação sem o planejamento voltado a sua capacidade de infiltração associada a eventos climáticos que aumentem os índices pluviométricos na região poderão acarretar em enchentes e inundações, por diminuírem o tempo para o escoamento superficial e o tempo de concentração das águas no córrego Imbirussu.

\section{CONCLUSÃO}

Com a análise dos dados morfométricos demonstrou-se que a microbacia do Córrego Imbirussu apresenta baixa probabilidade de enchentes devido a sua forma alongada, pobre densidade de drenagem, por ser uma bacia de $3^{\circ}$ ordem, ou seja, com baixo grau de ramificação, indicando que a área é de fácil à média permeabilidade e que a baixa variação de elevação não à torna susceptível a grandes variações de temperatura e precipitação, assim como a baixa declividade apresentada em seu perfil longitudinal indica que a água escoa em baixa velocidade e que por possuir um relevo plano/praticamente plano na maior porção de sua área deduz-se que o seu escoamento superficial é lento e que em condições naturais há boa capacidade de absorção.

A partir destas análises pode-se afirmar que os impactos ambientais ocasionados por enchentes na região urbana do Imbirussu estão associados à impermeabilização do solo e a ocupação nas proximidades de fundo de vale, principalmente na área de confluência do córrego Imbirussu com o córrego Cerradinho onde concentra-se o maior fluxo de água acumulado dentro da área urbana.

Portanto, o processo de uso e ocupação do solo na porção a jusante da microbacia deve ocorrer de forma planejada, ou seja, seguindo diretrizes urbanísticas que possam garantir o máximo de proximidade da dinâmica natural do sistema de drenagem da microbacia, mantendo o nível de permeabilidade do solo e o tempo de escoamento superficial nas vertentes, pois, consequentemente evitarão problemas relacionados a enchentes e acúmulo de sedimentos nas proximidades da foz do canal principal. 


\section{REFERÊNCIAS}

ATTANASIO, C.M. Planos de manejo integrado de microbacias hidrográficas com uso agrícola: uma abordagem hidrológica na busca da sustentabilidade. 2004. 193p. Tese (Doutorado em Recursos Florestais) - Escola Superior de Agricultura "Luis de Queiroz", Universidade de São Paulo, Piracicaba, 2004.

ANTONIO, A. L. A. Análise das políticas públicas no atendimento as famílias atingidas pelas enchentes e inundações na região do Imbirussu - Campo Grande/MS (2007-20012). 2012. 74f. Dissertação (Mestrado em Meio Ambiente e Desenvolvimento Regional) - Universidade Anhanguera UNIDERP, Campo Grande.

CALIJURI, M.C.; BUBEL, A.P.M. Conceituação de Microbacias. In: LIMA, W de P.; ZAKIA, M.J.B. (Orgs.) As florestas plantadas e a água. Implementando o conceito da microbacia hidrográfica como unidade de planejamento. São Carlos: Ed. RiMA, 2006. 226p.

CAMPO GRANDE. Secretaria Municipal de Meio Ambiente e Desenvolvimento Urbano - SEMADUR. Qualidade das Águas Superficiais de Campo Grande: Relatório 2010. p. 136. Disponível em: http://www.pmcg.ms.gov.br/semadur/canaisTexto?id_can=6399. Acesso em 12 de out. 2012.

CARVALHO, T. M; BAYER, M. 2008. Utilização dos produtos da "Shuttle Radar Topography Mission" (SRTM) no mapeamento geomorfológico do Estado de Goiás. Revista Brasileira de

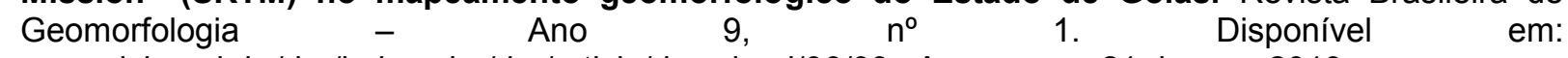
<www.lsie.unb.br/rbg/index.php/rbg/article/download/99/93> Acesso em: 21 de ago. 2013.

CHRISTOFOLETTI, A. Geomorfologia. 2a ed. São Paulo: Edgar Blücher, 1980.

CHRISTOFOLETTI, A. Geomorfologia fluvial. 1ª ed. São Paulo: Edgar Blücher, 1981.

ELESBON, A.A.A.; GUEDES, H.A.S.; SILVA, D.D.; OLIVEIRA, I.C. Uso de dados SRTM e plataforma SIG na caracterização morfométrica da bacia hidrográfica do braço norte do rio São Mateus Brasil. Revista Escola de Minas, v.64, n.3, p.281-288, 2011.

EMBRAPA - Empresa Brasileira de Pesquisa Agropecuária. Centro Nacional de Pesquisa de Solos. Sistema brasileiro de classificação de solos. 2.ed, Brasília: Embrapa Produção de Informação. Rio de Janeiro, 2006, 306p.

IBGE - Instituto Brasileiro de Geografia e Estatística. Manual técnico de Geomorfologia / IBGE, Coordenação de Recursos naturais e Estudos Ambientais. - 2. ed. - Rio de Janeiro : IBGE, 2009.

PLANURB. Instituto Municipal de Planejamento Urbano. Carta geotécnica de Campo Grande-MS. 1991. Disponível em: < www.pmcg.ms.gov.br/egov/downloadFile.php?id=19...> Acesso em 15 de ago. 2013.

SANTOS, R. S. Planejamento ambiental. Teoria e prática. 1 ed. São Paulo: Oficina de textos, 2004. $23 \mathrm{p} ; 43 \mathrm{p}$.

TEODORO, V. L. I., TEIXEIRA, D. COSTA, T. J. L., FULLER, B. B. O Conceito de bacia hidrográfica e a importância da caracterização morfométrica para o entendimento da dinâmica ambiental local. Revista Uniara, n.20, 2007.

TONELLO, K.C. Análise hidroambiental da bacia hidrográfica da cachoeira das Pombas, Guanhães, MG. 2005. 69p. Tese (Doutorado em Ciências Florestal) - Universidade Federal de Viçosa, Viçosa, 2005. 

Recursos Hídricos

VILLELA, S.M., MATTOS, A. Hidrologia Aplicada. São Paulo: McGraw - Hill do Brasil, 1975, 245p. 